\title{
Crafting Disaster Risk Science: Environmental and geographical science sans frontières
}

\author{
Ailsa Holloway
}

$\mathrm{I}^{\mathrm{n}}$

n keeping with the University of Cape Town's commitment to

social responsiveness (http://www.socialresponsiveness.uct.ac.za/), this article traces the process that underpinned the development and introduction of a postgraduate programme in Disaster Risk Science (DRS). It foregrounds the programme's conceptualisation within the Department of Environmental and Geographical Science (EGS) at the University of Cape Town (UCT), with particular emphasis on examining how disciplinary and theoretical coherence was balanced with cross-disciplinary application and social responsiveness.

The article begins by describing the contextual conditions external to UCT's formal teaching and learning environment that provided the necessary impetus for the new programme. It also traces the iterative interaction between context and curriculum that occurred over the period 1998-2008. This engagement was facilitated and mediated by the Disaster Mitigation for Sustainable Livelihoods Programme (DiMP), an interfacing research and advocacy unit, located within 
UCT's Department of Environmental and Geographical Science (EGS). ${ }^{1}$ An explanation of subsequent content and sequencing of the postgraduate curriculum then follow. They illustrate the programme's continued engagement with South Africa's newly promulgated disaster management legislation, as well as its relevance and rigour in relation to the complex risk environment of South Africa's Western Cape. The article continues by reflecting on the DRS programme's positive contributions both to scholarship and to risk management practice. It concludes by critically examining the pervasive and often dispiriting obstacles that constrained the new programme and that continue to challenge its institutional sustainability.

FRAMING DISASTER RISK FOR THE PURPOSE OF TEACHING AND LEARNING A fundamental expectation of higher education institutions is that they will continuously critique and evolve processes of scholarship that are academically rigorous and socially relevant. With respect to the DRS academic programme, it is particularly significant that its impetus originated in constituencies largely external to UCT. Specifically, the programme was 'driven-in' by a montage of contextual and societal processes, including the conceptual and ideological reorientation of the disasters discourse in the 1990s. It was also informed by an urgency to address and reverse the historic estrangement between African higher education institutions and the disasters domain, as well as the Republic of South Africa's ambitious aspirations to reform its disaster management legislation. Together, these provided much of the momentum, rationale and interfacing architecture necessary for strengthening UCT's scholarly engagement in the disasters domain.

THE GLOBAL CONTEXT

The past ten to fifteen years have been marked by a global reorientation of the disasters discourse, most significantly illustrated by the widespread acceptance of disaster risk reduction as a developmental imperative. This repositioning of the 'disasters' domain has also served to counter its more narrowly defined historic preoccupation with spectacular disaster events.

Scholarly impetus for this transition had in fact been building incrementally since the 1980s, drawing heavily on evidence collected

${ }^{1}$ The author acknowledges the potential for bias in this article, given her role in establishing DiMP and in initiating and implementing UCT's postgraduate programme in Disaster Risk Science. DiMP and the academic programme are currently undergoing review. 
from disasters in the 1970s and 80s that showed disaster losses to be significantly influenced by pre-existing social and economic vulnerability conditions. Similarly, it reflected mounting evidence of disproportionate levels of disaster loss and hardship borne by the urban and rural poor, especially those in developing countries (Blaikie et al. 1994; Hewitt 1997; Pelling 2003; Wisner et al. 2004; among others).

The shift in scholarly attention to vulnerability and risk reduction was also accompanied by vigorous international advocacy, notably by the United Nations International Strategy for Disaster Reduction (UN / ISDR) (http: / / www.unisdr.org /) and its 1990s predecessor, the International Decade for Natural Disaster Reduction (http:// www.reliefweb.int/; see also http:/ / www.unisdr.org for further information). While both global processes actively promoted the developmental reduction of disaster risks, ISDR efforts have been further advanced by the Hyogo Framework for Action 2005-2015 (http://www.unisdr.org/).

The past decade has been marked by the emergence of a wideranging vocabulary related to disasters and risks. The UNISDR has made particular effort to align terms and definitions that are frequently used. For instance, 'disaster risk' is defined as the 'potential disaster losses in lives, health status, livelihoods, assets and services which could occur to a particular community or society over some specific future time period'. Other definitions may be accessed online at: http:/ / www.unisdr.org/ eng/terminology/terminology2009-eng.html.

This global framework, an outcome of the World Conference on Disaster Reduction in January 2005, places specific emphasis on building the resilience of nations and communities to disasters (ISDR 2005). It explicitly calls for integrating disaster risk reduction into sustainable development policies and planning; the development and strengthening of institutions, mechanisms and capacities to build resilience to hazards; and the systematic incorporation of risk reduction into emergency preparedness, response and recovery programmes (ISDR 2005).

DisAster Response in Africa

Regrettably, the constructive engagement across academic and practitioner constituencies that reoriented global thinking on disasters 
has not prevailed in Africa. This is ironic given the continent's disaster risk profile, which, along with the scale of sustained international humanitarian assistance, indeed implies significant 'disaster-proneness'. ${ }^{2}$ It could be argued that the entrenched conflation of highly visible international aid with conceptions of African 'disasters' has, in itself, contributed to the estrangement of the continent's higher education institutions from meaningful engagement with the broader disasters domain. Furthermore, while consolidated emergency appeals and highly visible international humanitarian aid have been and remain the primary intervention mode for Africa's 'loud and visible' emergencies (Domini et al. 2008; see also http: / / www.reliefweb.int/), they simultaneously and unambiguously highlight significant shortfalls in local capacity and skilled human resources to address the continent's risks.

This conclusion resonates with findings by the Commission of the African Union, UN/ISDR and the World Bank, who jointly lamented that Africa's capacity to realize its developmental risk reduction aspirations remain significantly hampered by 'low knowledge, skills, competencies, staff and information at all levels' (Bhavnani et al. 2008, p. 43). Their report similarly highlights the continent's 'lack of technically-oriented human resources', and specifically identified the need for cross-sectoral training and strengthening of capabilities in relation to hydrometeorological threats (Bhavnani et al. 2008, p. 44).

Therefore, while there is no question that international relief has significantly alleviated disaster-related hardship and suffering across the continent, its focus on humanitarian and operational imperatives has seldom, if ever, allowed for engagement with Africa's institutions of higher learning. Moreover, international humanitarian assistance has repeatedly 'overlooked' the role played by higher education institutions in developing strategic human capacity to manage future or even recurrent risks. More importantly, it has signalled that the disasters domain is neither relevant to local discourse, nor a legitimate field of core scholarship and practice. Such outcomes are clearly contrary to the rationale that argues for strengthened human resources in the continent, and which, by necessity, require the engagement of Africa's institutions of higher education (Holloway 2009).

${ }^{2}$ OECD humanitarian response contributions to Africa for the period 1995-2006 have been conservatively estimated at USD 29 billion (Development Initiatives 2008) (http:/ / www. globalhumanitarianassistance.org) 
South Africa's transition to deVelopmental RISK REDUCtion

South Africa's experience of disaster management policy and law reform processes provides an important contextual driver to UCT's DRS programme as it departs significantly from this continental precedent. It also illustrates the value of the iterative engagement between South African higher education institutions and government that spanned almost a decade and which has continued. The vigorous character of this interaction is also credited with contributing substantially to the risk reduction focus of South Africa's 2002 Disaster Management Act and its subsequent national implementation framework (http:/ / www.ndmc.gov.za/). Significantly, both the law and framework explicitly underlined 'education, training and disaster management research' as priorities.

In the South African context, this concerted call for strengthened education, training and research acknowledged the urgent need for skilled human resources to implement the new legislation. However, it also represented tacit understanding of the complicated history and reputation of disaster management within South Africa that could be traced back through 'civil protection' to 'civil defence' and ultimately to its roots in 'national defence' and the armed forces. Furthermore, it implicitly placed obligations on the country's teaching and learning institutions to facilitate the field's transformation from its entrenched and historic preoccupation with a crisis-oriented 'militaristic response' into a socially responsive domain underpinned by developmental risk and vulnerability reduction (Pelling \& Holloway 2006).

It is in this context that the Disaster Mitigation for Sustainable Livelihoods Programme (DiMP) at UCT becomes relevant, both in its contribution to national policy and legislation, as well as through its provision of disaster risk-related education, training and research following the promulgation of the law in 2003. (For more information on DiMP, see: http:/ / www.riskreductionafrica.org/.)

Located within UCT's Department of Environmental and Geographical Science, DiMP's establishment in 1998 was motivated by southern Africa's intensifying drought and flood risk profile during the 1990s, as well as its growing dependence on international humanitarian aid. This period was also notable for its suite of high profile, internationally funded 'drought' and 'disaster management' 
workshops and training courses. The majority of the capacity building initiatives of that decade, however, were led by higher education institutions located abroad, which, unfortunately, were not sustained beyond their original project cycle.

The growing evidence of southern Africa's intensifying risk profile, combined with marked shortfalls in skilled human resources and persisting disconnect between the region's higher education institutions and the broader disaster management enterprise, as well as the inadequacies of internationally-driven 'training' initiatives, provided the impetus for the author to establish DiMP. Fortuitously, the Unit's inception also coincided with efforts by the postapartheid government to reform its out-of-date disaster management legislation. This provided a meaningful and robust context for university-society engagement as well as access to numerous stakeholders during the protracted policy and legislative reform process (Pelling \& Holloway 2006).

Since the law's promulgation, this initial relationship has been sustained and reinforced in the form of at least ten commissioned research, policy and training initiatives. The multi-stakeholder character of such work has also continued to provide nuanced insights into the knowledge and skills needed to strengthen national and local disaster risk management capacity. Moreover, its socially responsive character, grounded in the Western Cape's complex risk context, has significantly informed the content and curricula of DiMP's professional short courses and the formal DRS programme.

\section{FUSING CONTEXT WITH CONTENT: CONCEPTUALIZING THE DRS CURRICULUM}

Since the 2003 Disaster Management Act, external demands from government and interest groups for socially relevant disaster risk scholarship have been intense and unrelenting. However, the reality of weak continental experience in disaster risk-related education, combined with constrained internal teaching capacity, cautioned against a hasty curriculum response. As a result, the programme unfolded incrementally over a five-year period, coinciding with transitions in national disaster management policy and law. This iterative process of 'fusing context with content' was further enabled by the identification of three underpinning imperatives: disciplinary coherence within environmental and geographical science; alignment 
with transformative disaster management policy and practice; and social responsiveness to the Western Cape's disaster risk profile. Thus, the resulting programme, both in its conceptualization as well as its implementation, substantially converged with transdisciplinary learning approaches, despite its disciplinary location within environmental and geographical science.

The first key priority for the new academic programme was establishing disciplinary coherence within the field of environmental and geographical science. This objective sought to avoid the pitfalls that can accompany coarsely crafted efforts at 'mainstreaming' an emerging cross-cutting domain, or attempts to 'cut and paste' it superficially into an umbrella discipline. Disciplinary alignment also represented an essential precondition for framing the curriculum's scholarly identity and directing its social responsiveness.

Fortunately, the discipline of geography has an impressive scholarly tradition in the broad domain of hazards, vulnerability and disasters. Indeed, much of the global intellectual leadership in the society-environment interface relating to disasters can be directly attributed to the discipline. This has been and continues to be wideranging, extending, on one hand, from a detailed focus on natural hazards and the disasters they trigger (for instance, Alexander 1993; Bryant 1991; Burton, Kates \& White 1993; Smith \& Petley 2009) to applied publications that strengthen disaster and risk management policy and practice (such as Handmer \& Dovers 2007; Handmer \& Haynes 2008). The discipline, particularly through its expression in human geography, has also enhanced scholarly understanding of the social vulnerability conditions that increase the likelihood of loss and hardship (Blaikie et al. 1994; Hewitt 1997; Pelling 2003; Wisner et al. 2004, among others). This extensive work has vigorously underlined the plight of the urban and rural poor, especially those in developing countries, as bearing disproportionate levels of disaster loss and hardship.

It is the conceptual and empirical work in relation to natural hazards and human vulnerability that significantly underpinned the emergence of the concept of disaster risk in the 1990s. This has effectively repositioned the 'disasters domain' as a socially responsive, developmental priority. 
The DRS curriculum drew heavily from this rich geography literature, nuancing it further to reflect disaster risk application and contextual imperatives relevant to South Africa, and eventually defining disaster risk science as:

The systematic study of disaster risks, their determinants and consequences in order to inform disaster risk management and promote sustainable development. (Holloway, 2005)

The following figure unpacks this definition to demonstrate its articulation within the domain of environmental and geographical science as well as its application in relation to disaster risk

\begin{tabular}{|c|c|}
\hline \multicolumn{2}{|c|}{$\begin{array}{c}\text { Figure } 1 \\
\text { Definition of Disaster Risk Science }\end{array}$} \\
\hline $\begin{array}{l}\text { Disaster risk } \\
\text { interpreted through } \\
\text { Environmental \& } \\
\text { Geographical } \\
\text { Science lens }\end{array}$ & $\begin{array}{l}\text { Disaster Risk Science is: } \\
\text { The systematic study of disaster risks, } \\
\text { their determinants and consequences, }\end{array}$ \\
\hline $\begin{array}{l}\text { Purposeful } \\
\text { engagement with } \\
\text { RSA disaster } \\
\text { management policy } \\
\text { \& legislation }\end{array}$ & $\begin{array}{l}\text { in order to: } \\
\text { - inform disaster risk management, } \\
\text { and }\end{array}$ \\
\hline $\begin{array}{l}\text { Social } \\
\text { responsiveness to } \\
\text { risk \& vulnerability } \\
\text { profile of the } \\
\text { Western Cape }\end{array}$ & - promote sustainable development \\
\hline
\end{tabular}

management and social vulnerability reduction imperatives. With respect to the requirement for theoretical and disciplinary coherence within environmental and geographical science, the definition intentionally conceptualized disaster risk science as a field directed to purposive enquiry, rather than one oriented to practice. However, to ensure its coherence in an applied context, disaster risk 
science was also conceptualized to align with transformative disaster management policy and practice; that is, to reflexively inform and be informed by risk management imperatives.

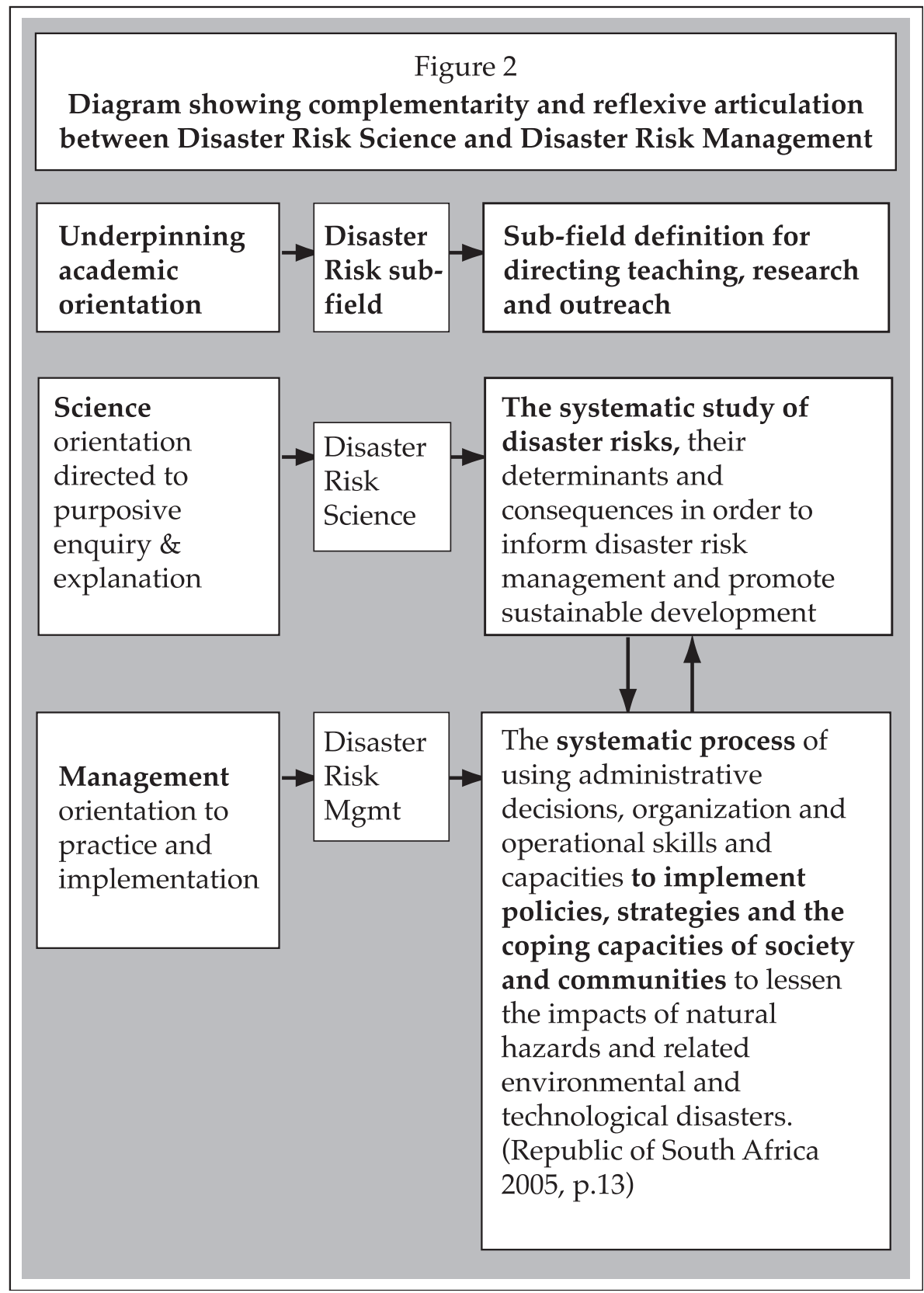

This is significant as it differentiates DRS from disaster risk management, a field that explicitly foregrounds practice and implementation. The separate but complementary emphases are 
viewed as analogous to those in the health sciences, in which epidemiology, defined as 'the study of the occurrence of disease' (Rothman 1986, p. 23), informs the practice of public health, but is not a field directly responsible for health care service delivery.

The reflexive relationship between disaster risk science and disaster risk management is illustrated in Figure 2 above. The third crucial dimension of the DRS academic programme was a focus on university-society engagement, which framed not only the formal curriculum, but also its socially responsive research orientation. In this context, the DRS definition also provided for selective attention to disaster risks of social and developmental relevance within the Western Cape. The scope and extent of these concerns is pointedly described below in the Provincial Disaster Management Framework of the Western Cape:

many of the Province's formally 'declared' disasters are triggered by extreme weather and are characterized by largescale informal settlement, veld (wild-land) and urban fringe fires, severe wind and rain storms, flash-floods and drought ... These relatively rare events classified as disasters are exceeded by many 'unclassified' significant events that are managed locally. The Province's past 'declared' events are even more dramatically outnumbered by the thousands of small and medium-size disaster events that exact cumulative losses on households and local authorities every year'. (http: / www. capegateway.gov.za/)

This summary of the Western Cape's disaster profile points to disaster risks that neither result in catastrophic losses, nor tens of thousands of deaths, as is characteristic of disaster events profiled in the international media. Yet, the disaster risk thematic is still critical from both developmental and humanitarian perspectives, especially in the Western Cape's hundreds of crowded and underserved informal settlements exposed to severe weather, flooding and destructive fires. It was this specific disaster risk context, despite its low profile in global publications such as the 2009 United Nations Global Assessment Report on Disaster Risk Reduction (http:// www.unisdr.org $/$ ) that the DRS programme sought to examine and address. In the context of the Western Cape's disaster risk profile, such an integrated socially-responsive interface was viewed as 'non- 
negotiable', acknowledging the widespread and increasing social hardship associated with recurrent 'small and medium scale' disaster events throughout the province, as well as the Western Cape's seasonal exposure to climate extremes, severe weather, flooding and devastating fires.

DISASTER RISK SCIENCE: AN EMERGING TRANSDISCIPLINARY DOMAIN Disaster risk science exhibits many of the characteristics specifically attributed to transdisciplinary processes of knowledge production - approaches that cut across or 'transgress' recognized disciplinary borders. Increasingly, transdisciplinary approaches are viewed as a robust means for understanding and addressing complex contemporary problems that are not amenable to disciplinary solutions alone (Horlick-Jones \& Sime 2004; Max-Neef 2005). They are further differentiated from multidisciplinary efforts by their exchange of elements 'across disciplinary boundaries in an evolved methodology which transcends "pure" disciplines' (Horlick-Jones \& Sime 2004).

Gibbons et al. (1994) significantly advanced understanding of transdisciplinary knowledge production by identifying Mode 1 and Mode 2 knowledges. While Mode 1 knowledge production is viewed as consistent with more orthodox disciplinary-based research, Mode 2 knowledge draws on both disciplinary and non-disciplinary sources of knowledge and is reflexively generated by multiple actors in a context of application (Gibbons et al. 1994, p. 3).

With specific reference to transdisciplinary learning, two clear preconditions are also underlined; the mastery of Mode 1 'foundational knowledge' (Gibbons et al. 1994; Muller 2000; Winberg 2006) and the provision of an enabling 'transaction space' that facilitates rigorous university-society dialogue and engagement (Nowotny et al. 2001; Winberg 2006).

Transaction spaces are seen to facilitate socially relevant knowledge production processes, enabling the 'co-evolution of knowledge producers and society' (Winberg 2006). They provide the means and processes by which macro, meso and micro concerns can 'speak to' higher education - as well as the means by which educators can 'talk back' to other contexts. 
In many ways, the unfolding DRS programme and its subsequent implementation provide a clear and valuable example of what Gibbons (2005) terms 'the new contract' between universities and society, one which reflects this 'joint production of knowledge by society and science' (Gibbons 2005). The disaster risk science programme, both in its conceptualisation as well as its transdisciplinary curriculum design, also conforms closely with the attributes of a Mode 2 knowledge production process (Gibbons et al. 1994, p. vii). This is evidenced by the programme's evolution through an iterative and reflexive articulation of environmental and geographical science in the context of South Africa's disaster risk management and social development imperatives.

The programme's apparent effectiveness in generating skilled human resources and contextually relevant disaster risk research also illustrates the coherence between its disciplinary foundation and social orientation. From the perspective of an applied postgraduate programme, it is clear that a robust 'Mode 1' environmental and geographical science undergraduate foundation was a necessary requirement (http:/ / www.egs.uct.ac.za). At the same time, the Disaster Mitigation for Sustainable Livelihoods Programme (DiMP) effectively 'opened up' the disaster risk transaction space, facilitating an engagement between the university and broader community that had not previously existed. This occurred through a wide range of activities, including commissioned research, disaster management policy development, practitioner training, and engagement with a diversity of government, civil society and international stakeholders. The university-society engagement further allowed the incremental generation of a curriculum that was both technically sound as well as socially robust. This has been measurably reflected in exploratory disaster risk research on informal dwelling fires in Cape Town by postgraduate students (Smith 2005; Morrissey \& Taylor 2006; Pharoah 2008) as well as ex post studies of severe weather events that exacted economic and social losses (to access postgraduate papers, see: http: / / www.egs.uct.ac.za). It was also apparent in the conceptualization and implementation of relevant professional 'Disasters and Development' short courses, attended by more than 300 practitioners from $2000-06$. As one senior provincial official has stated, 'I can trust the UCT graduates. They know what to do'. 


\section{From CURRICULUM DESIGN TO DELIVERY: CHALLENGES AND SOLUTIONS}

A pervasive challenge in framing the formal DRS teaching and learning process was the conspicuous absence of systematic scholarship related to disaster risk across Africa and from which the new curriculum could be adapted. While there are indeed numerous higher education courses that address the science of 'natural hazards' or 'human geography', their scope is not equivalent to that encompassed in the disaster risk field. Moreover, the urgency of the situation called for graduates with interdisciplinary disaster risk science skills and strong social responsiveness capacities within only a year (two semesters) of completing their undergraduate education. This generated a host of challenges and questions concerning sequencing, course content, preferred research methods and strategies to compensate for a seriously constrained literature relevant to the Western Cape's disaster risk profile.

With respect to curriculum sequencing, questions emerged concerning the timing of applied, focused and mentored service learning in disaster-prone areas. Additional ethical challenges arose in balancing the need for structured service learning with student safety in informal settlements that were often potentially dangerous and where levels of deprivation were traumatizing, even for mature postgraduate students.

From the perspective of content, questions also emerged on what constituted a responsible balance of disaster risk-specific and multidisciplinary content, given the diverse risk profile to be addressed and the limited teaching resources available. For instance, what proportion of content should address public health issues related to disaster risk ... or climate change concerns ... or humanitarian ethics? Similarly, given that DRS incorporated elements from both the natural and the social sciences, what specific research methods should the curriculum profile?

An early realization on course content was the glaring lack of published and unpublished literature directly applicable to the Western Cape disaster risk profile. Similarly, there were significant shortcomings in prevailing conceptions as well as popular misconceptions about urban risks within the province. This was compounded by a marked absence of robust research methods to study and understand the province's rapidly changing risk 
configurations. Such constraints are illustrated by comparing existing knowledge on wildfire ecology to that of informal settlement fires, both considered significant risks in the province. The first is characterized by a detailed, well-researched and scientifically solid body of literature; while the second remains conspicuously under-researched despite the widespread human hardship it generates and associated media profile http:// www.preventionweb.net/). Similarly, while established flood risk research methods have long existed within the fields of hydrology or freshwater ecology, these proved to have limited application in understanding and addressing the livelihood risks of the thousands of informal residents living in flood- and weather-exposed wetlands across the province.

\section{DELIVERING THE DRS CURRICULUM: INTEGRATION AND SEQUENCING}

The eventual DRS postgraduate curriculum reflected a sequenced transition that built theoretically and methodologically on an environmental and geographical science undergraduate foundation but added DRS-specific theory and practice. This process is illustrated below.

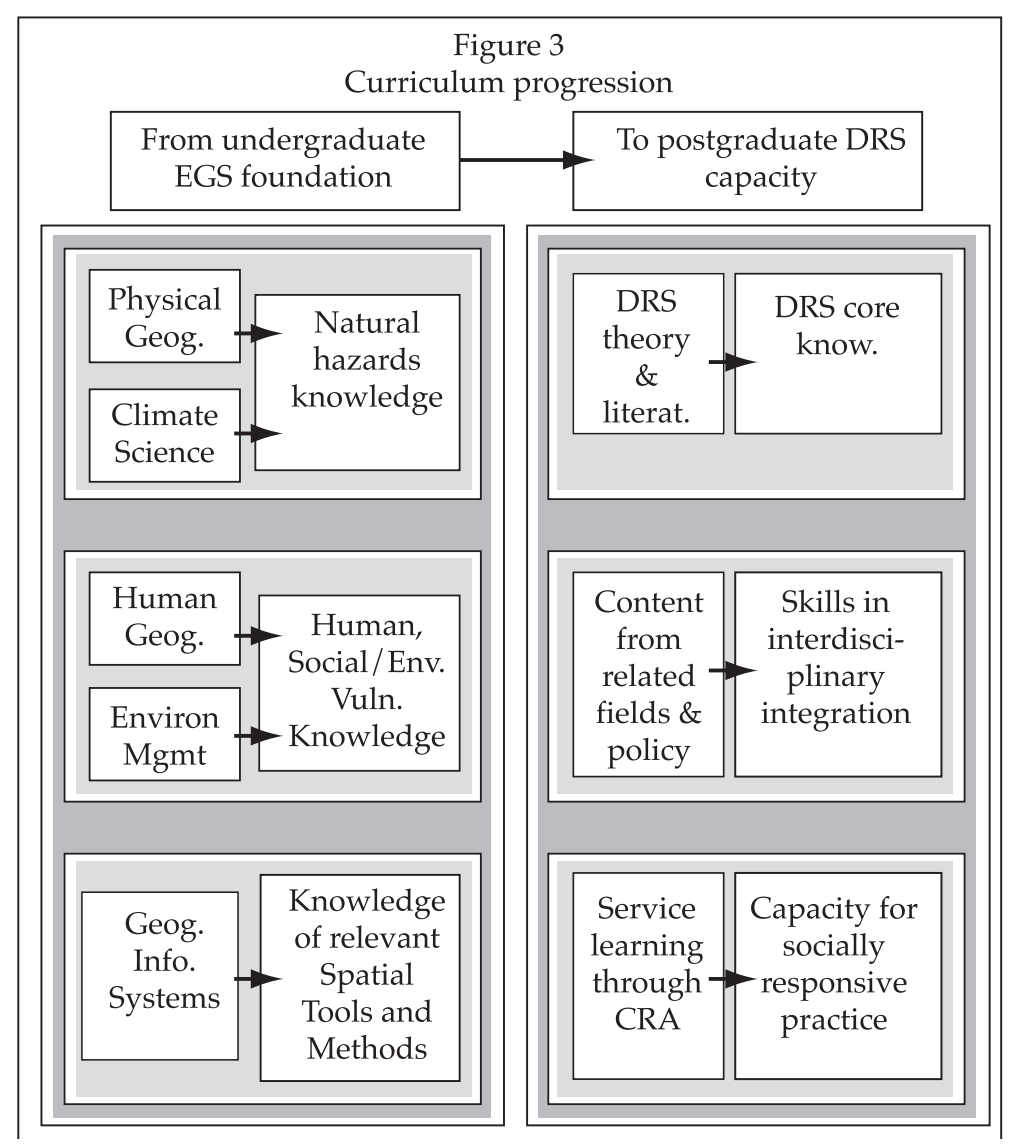


The DRS programme was crafted theoretically to rest on an undergraduate platform defined by the Mode 1 disciplinary requirements of environmental and geographical science. Conceptually, this was then 'stepped-up' to a post-graduate specialisation by focusing selectively on the 'hazards' and 'vulnerability' sub-themes introduced in the undergraduate curriculum, along with geospatial applications related to the disaster risk field (such as the use of global positioning systems and remote sensing technologies). The postgraduate programme extended application of these concepts and methods by introducing in-depth literature specifically related to disaster risk drawn from global sources as well as similar academic programmes in Europe, the Americas and Australasia. It also included additional content on climate change, public health, livelihoods and national disaster management policy, all considered essential interfacing knowledge areas to the disaster risk field in the context of the Western Cape.

Links between formal knowledge and socially responsive practice were consolidated through a community risk assessment (CRA) group exercise undertaken over several days in a disaster-prone informal settlement, jointly identified with the City of Cape Town's Disaster Management Centre. A key expectation of this service learning process was that both the participatory assessment process and findings would enhance community-based risk management in the settlement concerned, benefiting those who participated in the process.

Confidence in the academic robustness of the programme has grown since its introduction in 2004. This is reflected in the reports by independent examiners external to UCT who have consistently confirmed its academic rigour, including the quality of coursework, thoroughness of examinations and relevance of applied fieldwork. In addition, a comprehensive and independent panel review of both DiMP and the DRS programme is currently occurring. Valuable insights for further improving the programme are anticipated from this process.

Programme outcomes: the application of Socially Responsive science Since the DRS postgraduate programme began in 2004, it has generated numerous benefits with respect to skilled human capacity, 
unfolding disaster risk scholarship, development deliverables, and an emerging body of disaster risk knowledge that is relevant locally, nationally and internationally.

From 2004-09, approximately 35 students will have completed either DRS honours or masters degrees. Almost all honours graduates have either progressed to masters programmes either within DRS or other applied fields or have moved quickly into positions in government or non-governmental organizations. Some have been employed as entry-level disaster managers and others in nongovernmental development organisations. The cross-disciplinary character of the programme, combined with a focus on applied competencies, is seen to offer an impressively adaptable suite of skills, relevant to fields as diverse as climate change adaptation and integrated urban development.

Postgraduate theses on informal fires, severe weather events and urban flooding (http://www.riskreductionafrica.org/) have begun to generate an emerging but critical body of knowledge on complex risk configurations that, previously in Africa, had been poorly documented and understood. One such example is the reconceptualisation of the livelihood risks of informal residents in severe weather-exposed wetlands, which challenges established approaches to investigating riverine flood risk drawn from the disciplines of hydrology or freshwater ecology (Benjamin 2008). Another is the interrogation of the role played by weather variables widely used in wildfire danger rating systems as these apply to severe informal dwelling fires (Hackland 2007).

Similarly, since 2005, the service learning component of the programme has 'delivered' annually between one and three community risk assessments in identified risk-prone informal settlements. These assessments have become highly valued by local government and civil society stakeholders, as they are viewed as non-politicised vehicles for consensus-building on priority threats, especially in settlements with diverse and fragmented interest groups.

Significantly, DRS graduates also contribute to DiMP's commissioned disaster risk research, particularly as this applies to ex post studies of severe weather events. This growing body of 
knowledge (http: / / www.egs.uct.ac.za) now increasingly informs provincial and national discussions on adaptation to climate change. It has also guided policy formulation on development priorities such as strategic infrastructure planning as well as community development practice through publications such as Weathering the storm: participatory risk assessment in informal settlements (http:// www.preventionweb.net/), which provides advice on appropriate approaches for assessing and reducing risks in high risk areas.

Perhaps the most wide-reaching impact of the DRS programme, however, has been the actual conceptualisation of the academic programme itself, an approach that is proving to be transferable across disciplines, countries, languages and risk contexts. For example, USAID's Office of Foreign Disaster Assistance awarded \$USD 2.9 million to UCT to support and enable the Periperi U project to build disaster risk-related scholarship in ten higher education institutions across Africa from 2008-11 ( http:/ / www. riskreductionafrica.org $/$ ).

This unprecedented project, for both USAID and for disaster risk-related capacity development in Africa, sought specifically to build skilled disaster risk management human resource capacity through higher education institutions. The initiative is conceptualised as a cross-disciplinary collaboration to support selected academic programmes in fields as diverse as public health and seismic engineering in order to integrate disaster risk into their applied postgraduate courses. The rapid progress already made by the Periperi U consortium now signifies, for the first time in Africa, an emerging academic architecture for disaster risk-related scholarship and engagement across contexts, countries, languages and disciplines.

\section{Continuing tensions along Borders AND BOUNDARIES}

The unfolding of the DRS programme has, however, foregrounded many of the tensions documented in the development and practice of applied, transdisciplinary scholarship within contemporary university environments (Muller 2000; Waghid 2002; Winberg 2006). This has been particularly evident in the DRS case, given the programme's disciplinary positioning within the Department of Environmental and Geographical science within the Science Faculty. Such tensions are inevitable, given the socially-negotiated character of 
the disaster risk domain, which fluidly crosses a range of disciplines that include health sciences, economics, engineering and humanities.

Reconciling the tension between explicit requirements for internal disciplinary robustness and the transdisciplinary demands of the disaster risk field remains a persistent subtext and institutional challenge. From an academic perspective and by necessity, the disciplinary positioning of DRS within environmental and geographical science calls for in-depth knowledge of its umbrella domain. Furthermore, reflecting the need for disciplinary integrity, DRS curriculum content and graduate research are required to conform to quality assurance requirements framed by the disciplinary lens of environmental and geographical science. This is despite the fact that the intellectual scope and applied context of DRS reach well beyond these parameters. Muller (2000) contends that this is an expected consequence - that even when academics are 'deeply engaged in Mode 2, the evidence is that they continue to value their standing and participation in professional societies and the values and norms of their academic disciplines and that they continue to extol the virtues of peer review. That is to say, they continue to value a Mode 1 intellectual climate.'

Muller's observations resonate with the experience of the DRS programme, which, although deemed socially and technically valid from the lens of an applied discourse, falls short in conforming to the established disciplinary parameters of environmental and geographical science. It is particularly evidenced by the continued absence of any general operating budget support for DRS teaching and student supervision. This is despite consistent and competitive postgraduate student throughput since 2004, and growing demands for the programme by students and external role-players. Such constraints are increasingly countered by evidence of rigorous scholarship through established external examination processes, and an emerging 'research publication' profile. The current DiMP review also constitutes a valuable mechanism for a broader conversation with UCT leadership on greater institutional support for emerging fields, such as disaster risk science, as does documented evidence of fees and subsidy income generated from DRS-associated teaching and supervision. 


\section{CONCLUSION: DISASTER RISK SCIENCE OR 'EGS SANS FRONTIËRES'}

The disasters domain is, by its nature, diffuse and cross-cutting. Moreover, its transdisciplinary character not only embodies the concept of 'sans frontières' (without borders), but also obliges principled action in the service of humanity. In this context, and recognizing the inherent challenges of navigating a socially negotiated curriculum within a Faculty of Science, the article draws much of its inspiration from the independence and energy reflected by humanitarian organizations such as Médicins Sans Frontières.

There are other important implications to be drawn from the DRS programme; for, not only does it challenge deeply-entrenched stereotypes about disaster risks in Africa, it also provides evidence that strengthened human capacity in the continent is more than a future educational aspiration. It is an urgent developmental and humanitarian imperative - and it is long overdue.

\section{REFERENCES}

Alexander, D 1993, Natural disasters, UCL Press, London.

Bhavnani, R, Vordzorgbe, S, Owor, M \& Bousquet, F 2008, Report on the status of disaster risk reduction in the Sub-Saharan Africa region, Commission of the African Union, World Bank, UNISDR, Nairobi.

Blaikie, P, Cannon, T, Davis, I, \& Wisner, B 1994, At risk: Natural hazards, people's vulnerability and disasters, Routledge, New York.

Benjamin, MA 2008, Analysing urban flood risk in low-cost settlements of George, Western Cape, South Africa: Investigating physical and social dimensions, upublished MA Dissertation, University of Cape Town, Cape Town.

Bryant, E 1991, Natural hazards, Cambridge University Press, Cambridge.

Burton, I, Kates, RW \& White, GF, 1993, The environment as hazard, The Guilford Press, New York.

Development Initiatives 2008, Global humanitarian assistance 2007/2008, March 2008, Global Humanitarian Assistance Group, viewed 15 June 2009, http:/ / www. globalhumanitarianassistance.org

Domini, A, Fast, L, Hansen G, Harris, S, Minear, L, Mowjee, T, \& Wilder, A 2008, Humanitarian agenda 2015: Final report. The state of the humanitarian enterprise, Feinstein International Center, Tufts University, Boston, viewed 12 June 2009, http: / / www.reliefweb.int/

Gibbons, M, Limoges, C, C, Nowotny, H, Schwartzman, S, Scott, P \& Trow, M 1994, The new production of knowledge. The dynamics of science and research in contemporary societies, Sage, London.

Gibbons, M 2005, Engagement with the community: The emergence of a new social contract between society and science, unpublished paper presented at the Griffith University Community Engagement Workshop, South Bank Campus, Queensland.

Hackland, L 2007, Investigating the relationship between weather and the severity of urban fires: A study of informal settlement fires in the Cape Town metropolitan area, Unpublished MSc Proposal to the Department of Environmental and Geographical Science, University of Cape Town, Cape Town. 
Handmer, J \& Dovers, S, 2007, Handbook of disaster and emergency policies and institutions, Earthscan, UK and USA.

Handmer, J \& Haynes, K (eds) 2008, Community bushfire safety, CSIRO Publishing, Melbourne.

Hewitt, K 1997, Regions of risk: A geographical introduction to disasters, Addison Wesley Longman, Essex.

Holloway, A 2005, 'Disaster risk science in southern Africa: Taking it into the academic mainstream', in T Jeggle (ed.), Know Risk, UN/ISDR, Tudor Rose, Geneva, pp. 113-114.

Holloway, A \& Roomaney, R 2008, Weathering the storm: Participatory risk assessment in informal settlements, Periperi Publications, Cape Town, viewed 21 October 2009, http:// www.preventionweb.net/

Holloway, A 2009, 'Disaster risk in Africa: Dynamic discourse or dysfunctional dialogue?', paper presented at Conference on Conceptualisation of Risk in Africa, University of Bayreuth, November 2008, and forthcoming publication 2009, viewed 21 October 2009, http:/ / www.h-net.org/ announce/ show.cgi?ID=162295

Horlick-Jones, T \& Sime, J 2004, 'Living on the border: Knowledge risk and transdisciplinarity', Futures, vol. 36, pp. 441-456.

ISDR 2005, Hyogo framework for action 2005-2015: Building the resilience of nations and communities to disasters, World Conference on Disaster Reduction, Kobe, Hyogo, Japan, 18-22 January 2005, viewed 21 October 2009, http://www.unisdr.org/eng/hfa/hfa.htm

ISDR, 2009, Global assessment report on disaster risk reduction, United Nations, Geneva, Switzerland, viewed 12 June 2009, http:/ / www.preventionweb.net/ english/hyogo/gar/ report /index.php?id=1130\&pid:34\&pih:2

Max-Neef, MA, 2005, Foundations of transdisciplinarity, Ecological Economics, vol. 53, pp. $5-16$.

Muller, J 2000, 'What knowledge is of most worth for the millenial citizen?', in J Muller, Reclaiming knowledge: Social theory, curriculum and education policy, Routledge/Falmer, London and New York.

Morrissey, J \& Taylor, A 2006, 'Fire risk in informal settlements: A South African casestudy', Open House International, vol. 31, no. 1, pp98-105.

Nowotny, H, Scott, P, \& Gibbons, M 2001, Re-thinking science: Knowledge and the public in an age of uncertainty, Polity Press, Cambridge.

Pelling, M 2003, The vulnerability of cities: Natural disasters and social resilience, Earthscan, London.

Pelling, M \& Holloway, A 2006, 'Legislation for mainstreaming disaster risk reduction', TearFund, viewed 21 October 2009, http:/ / www.tearfund.org/webdocs/ website/ Campaigning/Policy\%20and\%20research/DRR\%20legislation.pdf)

Pelling, M \& Wisner, B (eds) 2008, Disaster risk reduction: Cases from urban Africa, Earthscan, London, viewed 21 October 2009, http:/ / www.tearfund.org/webdocs/website/ Campaigning/Policy\%20and\%20research/DRR\%20legislation.pdf

Pharoah, R 2008, 'Fire risk in informal settlements in Cape Town', in M Pelling \& B Wisner (eds), Disaster risk reduction: Cases from urban Africa, Earthscan, London, pp. 105-125.

Province of the Western Cape Provincial Gazette Extraordinary 2007, No 6455, The Western Cape disaster management framework: Disaster management act, 2002 (Act No. 57 of 2002), viewed 15 June 2009, http:/ / www.capegateway.gov.za/ Text/2008/5/ provin07ex gazdisaster_3_oct_2007.pdf 
Republic of South Africa, Government Gazette 2003, No. 24252, No. 57 of 2002, Disaster management act, 2002, Cape Town, viewed 15 June 2009, http:/ / www.ndmc.gov.za/ comp/ WebDocuments/disaster management act.pdf

Republic of South Africa, Government Gazette 2005, No. 27534, No. 654 of 2005, National disaster management framework, Cape Town, viewed 15 June 2009, http: / / www.ndmc.gov.za/

Rothman, K 1986, Modern epidemiology, Little, Brown and Company, Boston, Toronto.

Smith, H 2005, 'The relationship between settlement density and informal settlement fires: Case-study of Imizamo Yethu, Hout Bay and Joe Slovo, Cape Town metropolis', in P van Oosterom, S Zlatanova \& E M Fendel (eds), Geo-information for Disaster Management, Springer, Berlin, Heidelberg, pp. 1333-1355.

Smith, K \& Petley, D 2009, Environmental hazards: Assessing risk and reducing disaster, Routledge, London and New York.

University of Cape Town 2006, 'Social responsiveness report 2006', University of Cape Town, Cape Town, viewed 15 June 2009, http: / / www.socialresponsiveness.uct.ac.za/ usr/ social resp/reports/soc resp report2006.pdf

Waghid, Y 2002, Knowledge production and higher education transformation in South Africa: Towards reflexivity in university teaching, research and community service, Higher Education, vol. 43 , no. 4 , pp. $457-488$.

Winberg, C 2006, Undisciplining knowledge production: Development driven higher education in South Africa, Higher Education, vol. 51, no. 2, pp. 159-172.

Wisner B, Blaikie P, Cannon, T \& Davis, I 2004, At risk: Natural hazards, people's vulnerability and disasters (2nd edn), Routledge, London and New York. 